\section{Discussion}

The Health and Safety Executive has recently reviewed the toxicity of 1,1,1-trichloroethane in man and animals. ${ }^{1}$ The report highlights the acute cardiac toxicity of the compound found during trials as an inhalational anaesthetic in the 1950s. Hypotension and ventricular arrhythmias were observed. More recently several sudden deaths after solvent abuse or due to industrial accidents were attributed to a combination of factors such as narcosis, suffocation or hypercapnia (when rebreathing from a plastic bag), or cardiac arrhythmias possibly associated with hypercapnia or with exercise. ${ }^{13}$ Central nervous system damage with impairment of central control of respiration has also been suggested. ${ }^{4}$ In a single case cardiac arrhythmias were noted to persist for up to two weeks after exposure, ${ }^{5}$ but in that instance very high concentrations of 1,1,1-trichloroethane were present and urine assay showed continuing excretion of 1,1,1-trichloroethane and 1,1,2-trichloroethane during the period of observation. Chronic cardiac toxicity has not been reported.

Our two cases show that chronic myocardial damage presenting either as ventricular arrhythmias or as left ventricular failure is a possible sequel to both long term industrial exposure and short term solvent abuse with trichloroethane. These cases are important and also unusual in that exposure to trichloroethane was comparatively "pure." This is uncommon among glue sniffers, who may abuse multiple compounds.

Of main concern is the possible provocation of symptoms or rapid deterioration by a volatile anaesthetic. Halothane (2-bromo-2chloro-1,1,1,-trifluoroethane) may produce cardiac arrhythmias by sensitisation to catecholamines; nevertheless, it is less toxic in this regard than other halogenated alkanes, ${ }^{6}$ though more so than the newer ethers such as isoflurane and enflurane. The circumstances in which our first patient presented and the second patient deteriorated suggest that preliminary damage was caused by trichloroethane. Possibly a subsequent cross reaction with halothane may have occurred. Endomyocardial biopsy rarely gives a specific diagnosis, as many pathological insults may result in a largely similar histological picture. It is striking, however, that the pathologist, without knowing the second patient's clinical history, suggested a subacute myocarditis superimposed on a picture compatible with longstanding damage.

Trichloroethane is a widely available solvent and degreasing agent, being found in various glues, typewriter correction fluid, dry cleaning aids, and plaster remover. Its acute toxicity has made it unsuitable as a volatile anaesthetic and its use as a carrier in aerosols was abandoned in the United States in 1973. Despite widespread abuse $^{3}$ interest has focused on sudden deaths after acute overdosage. Chronic cardiac damage has not been recognised as a hazard of repeated exposure. There is a chemical similarity to halothane (both agents are halogenated $2 \mathrm{C}$ hydrocarbons) but no prior evidence of interaction has been reported. We postulate that such an interaction may partly explain the cardiac deterioration in our two patients. These cases also illustrate that the cardiac damage sustained after exposure to trichloroethane may be severe and life threatening and may be irreversible.

We thank Dr E G J Olsen, of the National Heart Hospital, London, for the histological report in case 2 .

\section{References}

1 Health and Safety Executive. Toxicity review 9: 1,1,1-trichloroethane. London: HMSO, 1984

2 Feigenbaum H. Echocardiography. 3rd ed. Philadelphia: Lea and Febiger, 1981:550.

3 Thomas Y. Kicking the glue buzz. Sunday Times 1986;Oct 12:52.

4 Wise MG, Fisher JG, de la Pena AM. Trichloroethane (TCE) and central sleep apnea: a case study. f Toxicol Environ Health 1983;11:101-4.

5 Wright MF, Strobl DJ. 1,1,1-Trichloroethane cardiac toxicity: report of a case. $\mathcal{F}$ Am Osteopath Assoc 1984;84:285-8.

6 Marshall BE, Wollman H. General anesthetics. In: Gilman AG, Goodman LS, Rall TW, Murad F, eds. The pharmacological basis of therapeutics 7th ed. London: Macmillan, 1985:279.

(Accepted 23 January 1987)

\title{
Digoxin-like immunoreactive substance in patients with aneurysmal subarachnoid haemorrhage
}

\author{
E F M WIJDICKS, M VERMEULEN, P van BRUMMELEN, N C DEN BOER, J van GIJN
}

\begin{abstract}
Digoxin was measured by radioimmunoassay in the plasma of 25 patients with aneurysmal subarachnoid haemorrhage who had not received digoxin treatment. After heating the plasma an
\end{abstract}

\footnotetext{
Department of Neurology, University Hospital Dijkzigt, Rotterdam, The Netherlands

E F M WIJDICKS, MD, neurologist

$M$ VERMEULEN, MD, neurologist

Department of Nephrology, University Hospital, Leyden
P VAN BRUMMELEN, MD, nephrologist

Department of Clinical Chemistry, University Hospital (Sophia Children's Hospital), Rotterdam

N C DEN BOER, MSC, clinical biochemist

Department of Neurology, University Hospital, Utrecht J VAN GIJN, MD, professor of neurology

Correspondence to: Dr E F M Wijdicks, Department of Neurology, University Hospital of Utrecht, 3511 HG Utrecht, The Netherlands.
}

endogenous substance cross reacting with antibodies to digoxin was identified in 18 cases. The presence of this substance was significantly related to the total amount of blood and to the presence of blood in the frontal interhemispheric fissure and could not be explained by hypertension or intake of water and sodium. A negative sodium balance and volume depletion occurred more often in patients who were positive for digoxin, but this relation did not reach statistical significance.

It is concluded that a digoxin-like natriuretic factor is released in response to a subarachnoid haemorrhage, probably as a result of hypothalamic damage.

\section{Introduction}

Hyponatraemia may occur after aneurysmal subarachnoid haemorrhage. ${ }^{1}$ In a consecutive series of 134 patients 44 were noted to have hyponatraemia during the first two weeks after the initial haemorrhage. ${ }^{2}$ None of these patients suffered neurological deterioration directly attributable to the hyponatraemia, probably because sodium concentrations fell gradually and not below $120 \mathrm{mmol} / \mathrm{l}^{3}$ Nevertheless, patients with hyponatraemia had a 
higher risk of cerebral ischaemia, ${ }^{2}$ one of the main causes of morbidity after subarachnoid haemorrhage.

Hyponatraemia after subarachnoid haemorrhage has been attributed to the syndrome of inappropriate secretion of antidiuretic hormone. ${ }^{4}$ Recently it has been shown to be preceded by a negative sodium balance and to be associated with a decrease in plasma volume. $^{5-7}$ Vasopressin concentrations were raised initially but had decreased when hyponatraemia developed. ${ }^{\text {s }}$ Hence cerebral salt wasting as an explanation for hyponatraemia after subarachnoid haemorrhage ${ }^{8}$ seems more plausible than the syndrome of inappropriate secretion of antidiuretic hormone. The factor causing natriuresis after subarachnoid haemorrhage is not known.

We have studied patients with subarachnoid haemorrhage to see whether an endogenous digoxin-like substance, which enhances sodium excretion by inhibiting sodium transport in the kidney, ${ }^{9}$ was detectable in the plasma during the first days.

\section{Patients and methods}

We studied 25 consecutive patients with signs and symptoms of subarachnoid haemorrhage who showed computed tomographic evidence of blood in the basal cisterns indicating a ruptured aneurysm. Criteria for exclusion from the series were an interval of more than 48 hours since the haemorrhage, death within six days, endocrine disturbances, heart failure, renal failure, neoplasm, and treatment with diuretics, steroids, or digoxin. In 22 of the 25 patients an aneurysm was confirmed by angiography or at necropsy. In the other three patients angiography and surgery were contraindicated by advanced age (over 70 ) or impaired consciousness. Nevertheless, a ruptured aneurysm was considered highly probable in these patients owing to the presence of blood in the interhemispheric, suprasellar, or sylvian cisterns and the absence of evidence of any other cause of the haemorrhage. ${ }^{1011}$ All patients were under continuous observation in an intensive care unit and were studied for 10 days after admission. In most patients clipping of the aneurysm was carried out on the twelfth day.

\section{FLUID AND SODIUM BALANCE AND BLOOD PRESSURE}

We obtained daily measurements of electrolytes, blood urea nitrogen, creatinine, serum osmolality, and packed cell volume. All patients had a fluid intake of at least $1500 \mathrm{ml}$ per 24 hours. Sodium intake was calculated from the diet, which was specially prepared, and from the concentration of sodium in intravenous fluids. Sodium excretion was measured in 24 hour urine samples. Salt balance was considered negative when sodium excretion exceeded the daily intake. Loss of sodium from the skin or in faeces was not included in the calculation of sodium balance.

Mean blood pressure was calculated from four readings taken at six hour intervals-that is, 6, 12, 18, and 24 hours. Hypertension was defined as a mean blood pressure (diastolic pressure plus one third of the pulse pressure) of $120 \mathrm{~mm} \mathrm{Hg}$ or more on at least one day.

\section{RADIOIMMUNOASSAY FOR DIGOXIN IMMUNOACTIVITY}

The plasma concentration of digoxin-like factor was determined in blood drawn in heparinised plastic tubes, which was centrifuged and stored at $-70^{\circ} \mathrm{C}$. The magnitude of digoxin-like factor was determined by competitive displacement of iodine-125 labelled digoxin from antidigoxin antibodies relative to digoxin standards. Digoxin-like immunoreactive substance was measured by radioimmunoassay (RIANEM TM Digoxin, New England Nuclear, cat No NEA-082) using the procedure described by the manufacturer with a few modifications.

To increase sensitivity we examined different combinations of volumes for standards and samples and tracer and antiserum complex. Without performing an extensive search for the lowest detection limit possible we found the following modifications suitable for our study: volume of standards and samples was increased from 100 to $200 \mu \mathrm{l}$; volume of tracer was reduced from 500 to $200 \mu \mathrm{l}$; standards $0,0.05,0 \cdot 1,0 \cdot 2,0 \cdot 3,0.5,1 \cdot 0,2 \cdot 0$, and $4.0 \mu \mathrm{g}$ digoxin/l were prepared by dilution of $8.0 \mu \mathrm{g} / \mathrm{l}$ standard with zero standard. These modifications resulted in a typical standard curve with values for the normalised percentage of antigen bound to antibody of $100 \cdot 0$, $92 \cdot 2,86 \cdot 2,73 \cdot 5,65 \cdot 8,51 \cdot 1,33 \cdot 7,19 \cdot 3$, and $9 \cdot 0$, respectively. The lower limit of sensitivity was $0.05 \mu \mathrm{g} / 1$.

For the determination of digoxin-like immunoreactive substance samples were diluted $1 / 3$ with deionised water in glass tubes, placed in a boiling water bath for five minutes, and analysed as above. According to the dilution factor the lower limit of sensitivity rose to $0.2 \mu \mathrm{g} / \mathrm{l}$ for this procedure. This method results in release of the digoxin-like substance from its protein binding, thus enhancing measured immunoactivity. ${ }^{12}$

In the patients with subarachnoid haemorrhage plasma samples were taken on admission (day 0 ) and after six days before determinations of plasma volume. We also assayed plasma samples from 17 healthy volunteers and four newborn infants. ${ }^{13}$

\section{PLASMA VOLUME DETERMINATION}

All patients had their plasma volume measured on admission and again on the sixth day. Measurement was by the isotope dilution technique with iodine-131 labelled human serum albumin, as detailed elsewhere. ${ }^{5} \mathrm{We}$ expressed the results as total plasma volume and calculated the percentage change between the two measurements. We considered only a decrease of more than $10 \%$ to be substantial.

\section{VENTRICULAR SIZE AND AMOUNT AND SITE OF HAEMORRHAGE}

As a linear measurement of ventricular size we used the bicaudate indexthat is, the width of the frontal horns at the levels of the caudate nuclei divided by the corresponding diameter of the brain. The width of the third ventricle was measured on the slice at the point of maximal transverse diameter. The bicaudate index and width of the third ventricle were converted into a relative size by dividing the absolute values by the upper limit for age (unpublished data). ${ }^{14}$ An intraventricular haemorrhage was considered to be frank when more than one ventricle was completely filled with blood. The amount of cisternal haemorrhage was graded separately for each of the following cisterns on a scale of 0 to $3(0=$ no blood, $1=$ sedimentation of red blood cells in a cistern, $2=$ cistern or fissure partly filled with blood, 3 =cistern or fissure completely filled with blood): frontal interhemispheric fissure, quadrigeminal and paired suprasellar cisterns, ambient cisterns, basal sylvian fissures, and lateral sylvian fissures. ${ }^{14}$ The site of the haemorrhage was classified as $(a)$ subarachnoid blood with centre of the haemorrhage located in the frontal interhemispheric fissure (12 patients), and $(b)$ subarachnoid blood with centre of the haemorrhage located unilaterally in suprasellar cistern, sylvian fissure, or interpeduncular cistern (13 patients). ${ }^{15}$ Computed tomograms on admission were graded by two of us (EFMW and MV) without knowledge of the results of the digoxin immunoassay.

\section{STATISTICAL ANALYSIS}

Distributions in $2 \times 2$ tables were analysed by Fisher's exact probability test. The Mann-Whitney $U$ test was used for comparing unpaired samples because of small sample size and the assumption that values were not normally distributed. $p$ Values were calculated by two sided tests.

\section{Results}

Digoxin immunoassay values-Before being heated none of the plasma samples from the patients or volunteers contained detectable digoxin-like substance. By contrast, digoxin-like substance was found in all the newborn infants. (range $0 \cdot 2-0 \cdot 4 \mu \mathrm{g} / 1$, mean $0.3 \mu \mathrm{g} / \mathrm{l}$ ). On heating the samples digoxin-like substance was detected in one of the 17 volunteers $(0.2 \mu \mathrm{g} / \mathrm{l})$, and in the four newborn infants concentrations ranged from 0.3 to $0.8 \mu \mathrm{g} / \mathrm{l}$ (mean $0.5 \mu \mathrm{g} / \mathrm{l}$ ). Eleven of the 25 patients with subarachnoid haemorrhage had detectable digoxin-like substance on admission; values in all patients ranged from zero to $0.5 \mu \mathrm{g} / 1$ (mean $0.2 \mu \mathrm{g} / \mathrm{l}$ ). On the sixth day after admission 17 patients had digoxin-like substance detected, concentrations in all patients ranging from zero to $0.8 \mu \mathrm{g} / \mathrm{l}$ (mean $0.3 \mu \mathrm{g} / \mathrm{l}$ ). Ten of the 25 patients had detectable concentrations in both samples and eight in only one sample, and in seven patients concentrations were undetectable on both occasions (fig 1). When the two measurements are taken together $72 \%$ of patients were positive for digoxin-like substance ( $95 \%$ confidence interval $51 \%$ to $88 \%$ ).

Digoxin-like substance, blood pressure, and fluid and sodium intake-We studied the incidence of hypertension after the haemorrhage and the intake of fluid and sodium as possible explanations for the presence of digoxin-like substance on the sixth day after admission. Hypertension occurred almost as often in patients with detectable digoxin values $(9 / 17 ; 53 \%)$ as in those without $(6 / 8 ; 75 \%$ ) (Fisher's exact test, $p=0 \cdot 42$ ). Blood urea nitrogen and creatinine concentrations remained normal in all patients. Sodium intake ranged from 205 to $1355 \mathrm{mmol}$ (mean $586 \mathrm{mmol}$ ) in patients positive for digoxin-like substance and from 135 to $850 \mathrm{mmol}$ (mean $609 \mathrm{mmol}$ ) in 
patients negative for digoxin-like substance (Mann-Whitney $U$ test, $z=0 \cdot 26$, $p=0.79$ ). Total fluid intake over five days ranged from 8.4 to 13.91 (mean 10.91 ) in the digoxin positive group and from 10.6 to 15.91 (mean 12.01) in the digoxin negative group; this difference was not significant (MannWhitney $U$ test, $z=1 \cdot 47, p=0 \cdot 14$ ). Fluid balance was similar in both groups of patients. Values of cumulative fluid balance ranged from -0.6 to 7.01 (mean 4.01 ) in the digoxin positive group and from -0.9 to 7.01 (mean 4.01 ) in patients without digoxin-like substance. No atrial arrhythmias were seen in any patient.

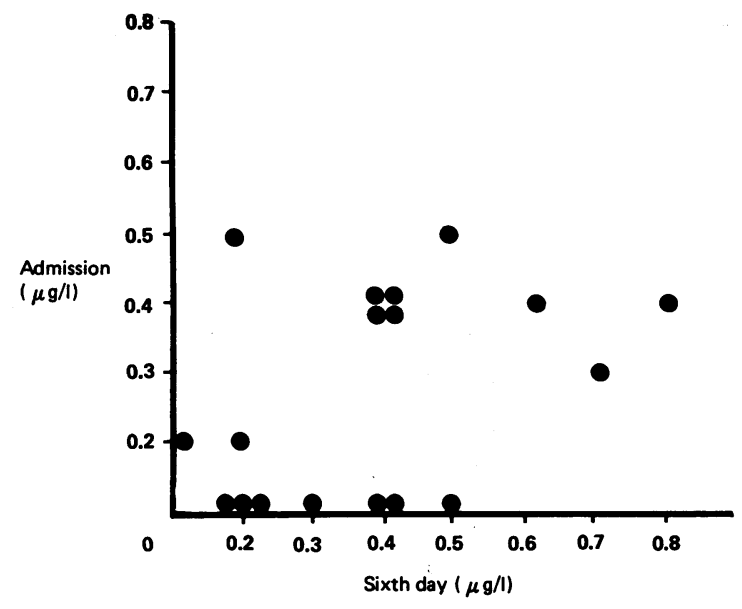

FIG 1 - Concentrations of digoxin-like substance in 25 patients with ruptured aneurysm. (Seven patients did not have detectable concentrations on admission or on sixth day.)
Digoxin-like substance and clinical and computed tomogram characteristicsThe table shows the distribution of loss of consciousness at the time of haemorrhage, Glasgow coma scores ${ }^{16}$ on admission, enlargement of lateral and third ventricles, and the presence of frank intraventricular haemorrhage on the initial computed tomogram in patients with and without digoxinlike substance. Patients with digoxin-like substance more often had

Clinical and computed tomographic features in 25 patients with and without digoxin-like substance after subarachnoid haemorrhage

\begin{tabular}{|c|c|c|c|}
\hline \multirow[b]{2}{*}{$\begin{array}{l}\text { Clinical and computed tomographic } \\
\text { characteristics }\end{array}$} & \multicolumn{2}{|c|}{ No (\%) of patients } & \multirow[b]{2}{*}{$\begin{array}{l}\text { Total } \\
(100 \%)\end{array}$} \\
\hline & $\begin{array}{c}\text { Digoxin-like } \\
\text { substance } \\
(n=18)\end{array}$ & $\begin{array}{l}\text { No digoxin-like } \\
\text { substance } \\
(\mathbf{n}=7)\end{array}$ & \\
\hline Loss of consciousness at ictus & $6(67)$ & $3(33)$ & 9 \\
\hline \multicolumn{4}{|l|}{ Glasgow coma score: } \\
\hline$<12$ & $2(100)$ & 0 & 2 \\
\hline 12,13 & $3(100)$ & 0 & 3 \\
\hline 14 & $13(65)$ & $7(35)$ & 20 \\
\hline Enlarged lateral ventricles & $5(100)$ & 0 & 5 \\
\hline Enlarged third ventricle & $10(83)$ & $2(17)$ & 12 \\
\hline Frank intraventricular haemorrhage & $5(71)$ & $2(29)$ & 7 \\
\hline \multicolumn{4}{|l|}{ Grade of cisternal haemorrhage*: } \\
\hline $0-5$ & $1(50)$ & $1(50)$ & 2 \\
\hline 6-10 & $4(50)$ & $4(50)$ & 8 \\
\hline $11-15$ & $6(75)$ & $2(25)$ & 8 \\
\hline $16-20$ & $4(100)$ & 0 & 4 \\
\hline $21-25$ & $3(100)$ & 0 & 3 \\
\hline 26-30 & 0 & 0 & 0 \\
\hline \multicolumn{4}{|l|}{ Site of subarachnoid blood $\star \star$ : } \\
\hline $\begin{array}{l}\text { Centre of haemorrhage in frontal } \\
\text { interhemispheric fissure }\end{array}$ & $11(92)$ & $1(8)$ & 12 \\
\hline Centre of baemorrhage in other cisterns or & & & \\
\hline fissures & $7(54)$ & 6(46) & 13 \\
\hline
\end{tabular}

${ }^{\star} \mathrm{p}=0.012$ (Mann-Whitney U test)

${ }_{\star \star} \mathrm{p}=0.02$ (Fisher's exact test).

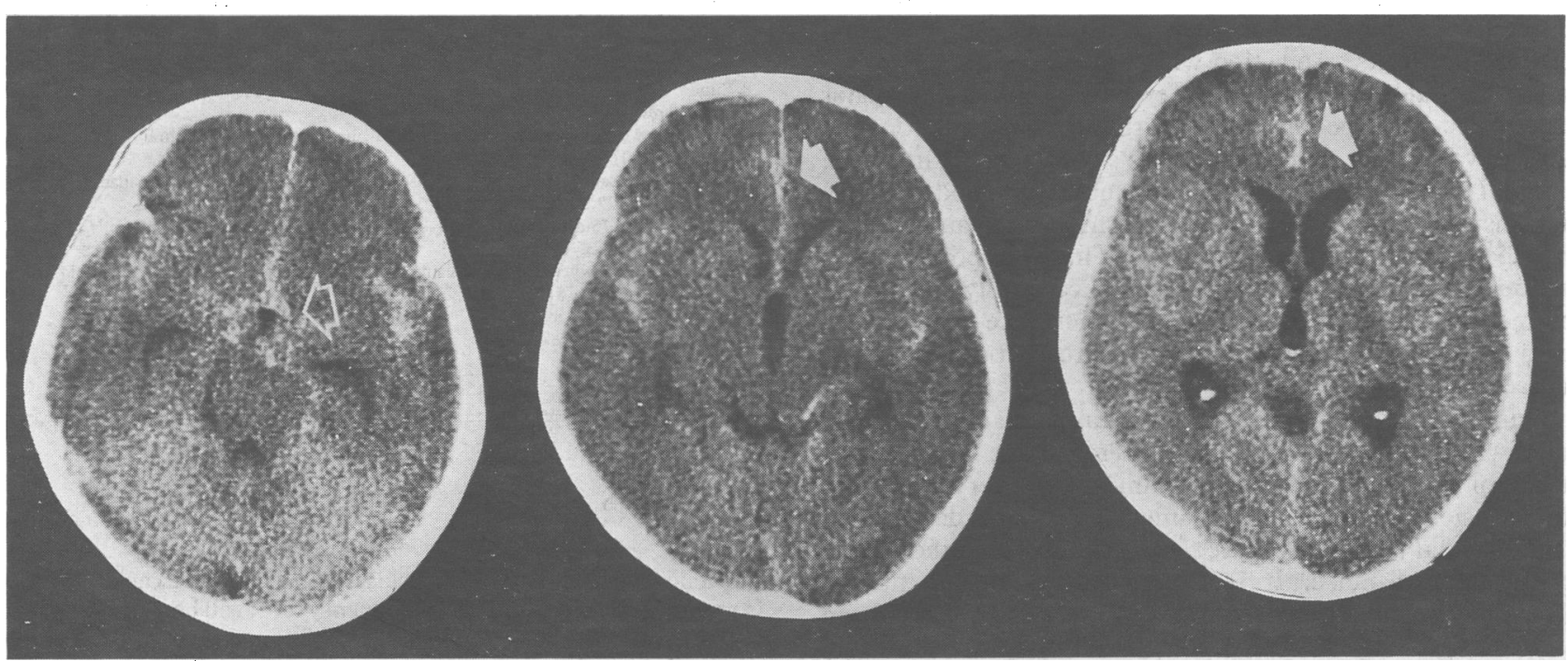

FIG 2-Computed tomogram of patient with diffusely distributed blood. Centre of haemorrhage located in frontal interhemispheric fissure (solid arrow), near hypothalamus (open arrow). Concentrations of digoxin-like substance were $0.4 \mu \mathrm{g} / \mathrm{l}$ on admission and $0.6 \mu \mathrm{g} / \mathrm{l}$ on sixth day.

Digoxin-like substance, sodium balance, and volume depletion-Given that the presence of digoxin-like substance on day 6 could not be explained by differences in blood pressure or in intake of water and sodium, the next question was whether the substance itself (on day 0 or 6) might have contributed to changes in sodium balance and plasma volume. A negative cumulative sodium balance over five days was found in 14 of the 18 patients who had detectable digoxin-like substance in one or both of the plasma samples and in three of the seven patients who had no detectable values in the two samples. This difference did not reach significance (Fisher's exact test, $p=0 \cdot 1)$. Cumulative sodium balance values ranged from -72 to $-179 \mathrm{mmol}$ (mean $-169 \mathrm{mmol}$ ) in the 14 digoxin positive patients and from 110 to $-370 \mathrm{mmol}$ (mean $-53 \mathrm{mmol}$ ) in the digoxin negative group (MannWhitney $\mathrm{U}$ test, $\mathrm{z}=0.09, \mathrm{p}=0.93$ ). Plasma volume decreased by more than $10 \%$ in 12 of the 18 digoxin positive patients and in three of the seven digoxin negative patients (Fisher's exact test, $p=0 \cdot 40$ ). impaired consciousness on admission and enlarged lateral and third ventricles on the first computed tomogram but none of these differences reached significance. The amount of cisternal blood seen on the initial computed tomogram was significantly associated with the presence of digoxin-like substance (Mann-Whitney $U$ test, $z=-2.49, p=0.012$ ). Predominance of subarachnoid blood in the interhemispheric fissure, suggesting rupture of an anterior communicating artery, was significantly associated with the presence of digoxin-like substance (Fisher's exact test, $p=0 \cdot 02$ ). Angiography or necropsy was performed in 10 of the 12 patients with subarachnoid blood mainly located in the frontal interhemispheric fissure on computed tomography, and an aneurysm of the anterior communicating artery was found in all (fig 2). Angiography or necropsy in 12 of the 13 patients with the centre of the haemorrhage in other cisterns or fissures showed an aneurysm at other sites in all cases (five aneurysms of middle cerebral artery, five of carotid artery, two at basilar bifurcation). 


\section{Discussion}

Before the description of the syndrome of inappropriate secretion of antidiuretic hormone ${ }^{4}$ natriuresis after subarachnoid haemorrhage was attributed to a putative natriuretic factor and was termed cerebral salt wasting. ${ }^{8}$ Our findings show that after subarachnoid haemorrhage a digoxin-like natriuretic substance is detectable in the plasma and that its release is related to cerebral factors such as the amount and site of the haemorrhage. Factors known to be associated with this substance in the plasma, such as hypertension ${ }^{17}$ and fluid and salt loading, ${ }^{1819}$ were similarly distributed between the patients with and without digoxin-like substance, and in none of the patients could renal failure $e^{20}$ or atrial arrhythmias $^{21}$ account for the reaction to digoxin antibodies. The presence of the substance was associated with extensive cisternal haemorrhage and with a distribution of blood suggesting a ruptured anterior cerebral artery aneurysm. These findings suggest that in patients with subarachnoid haemorrhage a cerebral factor is responsible for the release of digoxin-like substance.

In our patients with subarachnoid haemorrhage digoxin-like substance could be detected only after heating the plasma. In the control group of healthy hospital personnel heating the plasma samples disclosed a very low value in only one subject. Concentrations in the patients with subarachnoid haemorrhage were in the range found in newborn infants, which suggests that the finding has pathological relevance.

Digoxin-like substance has natriuretic properties in salt loaded healthy subjects and untreated hypertensive patients. ${ }^{17182223}$ Further evidence for its natriuretic activity was found in studies showing the inhibition of membrane bound sodium and potassium adenosine triphosphatase leading in turn to inhibition of sodium reabsorption in renal tubules. ${ }^{24}$ Our results also suggest an association between digoxin-like substance and natriuresis, but this association did not reach significance. A similar association was found between digoxin-like substance and volume depletion.

The clinical importance of natriuresis after subarachnoid haemorrhage lies in its association with volume depletion, ${ }^{2}$ which plays a part in cerebral ischaemia. ${ }^{25}$ Cerebral ischaemia is a major complication of subarachnoid haemorrhage. It is traditionally attributed to vasospasm, but many patients with vasospasm escape ischaemia ${ }^{26}$ It may be that hypovolaemia increases blood viscosity and that this in combination with vasospasm leads to an impaired cerebral blood flow and cerebral ischaemia. This is supported by the observation that cerebral ischaemia may successfully be treated by volume expansion ${ }^{27}$ and that the incidence of cerebral ischaemia increases in patients given fluid restriction to correct hyponatraemia. ${ }^{2}$

We found that the presence of digoxin-like substance was associated with extensive subarachnoid haemorrhage and also with an aneurysm of the anterior communicating artery. In both conditions lesions of the hypothalamus have been described, ${ }^{29}$ and it may be that these lesions are the crucial factor in the release of digoxin-like substance. It seems probable that the human hypothalamus contains a digoxin-like substance, as this has been found in oxen and guinea pigs. ${ }^{30}{ }^{31}$ An alternative explanation of the relation between blood in the interhemispheric fissure and the release of digoxin-like substance concerns not only the hypothalamus but also the heart. Areas of myofibrillar degeneration in the heart have been found in association with hypothalamic lesions after subarachnoid haemorrhage. ${ }^{32}$ Thus a ruptured anterior aneurysm or a large haemorrhage might result in a hypothalamic lesion which would lead to myofibrillar degeneration in the heart and the release of digoxin-like substance.

We acknowledge Mr T Weterings for laboratory work and thank Mrs J Doornbosch-Konijn for excellent secretarial help.

\section{References}

1 Dòczi T, Bende J, Huska E, et al. Syndrome of inappropriate secretion of antidiuretic hormone after subarachnoia nemorrhage. Neurosurgery 1981;4:394-6.

2 Wijdicks EFM, Vermeulen M, Hijdra A, et al. Hyponatremia and cerebral infarction in patients with ruptured intracranial ancurysms: is fluid restriction harmful? Anon Neurol 1985;18:137-40.
3 Arrieff AI, Llack F, Massry SG, et al. Neurological manifestation and morbidity of hyponatremia: correlation with brain water and electrolytes. Medicine 1976;55:121-9.

4 Schwartz WB, Bennet W, Curelop S, et al. A syndrome of renal sodium loss and hyponatremia probably resulting from inappropriate secretion of antidiuretic hormone. Am $\mathcal{F}$ Med 1957;23 529-42.

5 Wijdicks EFM, Vermeulen M, ten Haaf JA, et al. Volume depletion and natriuresis in patients with a ruptured intracranial aneurysm. Ann Neurol 1985;18:211-6.

6 Nelson PB, Seif SM, Gutal J, Robinson A. Hyponatremia and natriuresis following subarachnoid hemorrhage in a monkey model. If Neurosurg 1984;60:233-7.

7 Nelson PB, Seif SM, Marroon J, et al. Hyponatremia in intracranial disease, perhaps not the syndrome of inappropriate secretion of antidiuretic hormone (SIADH). $\mathcal{F}$ Neurosurg 1981;55: syndrome

8 Cort JH. Cerebral salt wasting. Lancet 1954;i:752-4.

9 De Wardener HE, MacGregor GA. The natriuretic hormone and essential hypertension. Lance 1982;i:1450-4.

10 Van Gijn J, van Dongen KJ. Computerized tomography in subarachnoid hemorrhage: difference between patients with and without an aneurysm on angiography. Neurology 1978;30:538-9.

11 Van Gijn J, van Dongen KJ, Vermeulen M, et al. Perimesencephalic hemorrhage: a nonaneurysmal and benign form of subarachnoid hemorrhage. Neurology 1985;35:493-7.

12 Valdes R, Graves SW, Becker SL. Protein binding of endogenous digoxin-immunoactive factors in human serum and its variation with clinical condition. $f$ Clin Endocrinol Metab 1985;60: $1135-43$.

13 Valdes R, Graves SW, Brown BA, et al. Endogenous substance in newborn infants causing false positive digoxin measurements. F Pediatr 1983;102:947-50.

14 Van Gijn J, Hijdra A, Wijdicks EFM, et al. Acute hydrocephalus after aneurysmal subarachnoid hemorrhage. $\mathcal{F}$ Neurosurg 1985;63:355-62.

15 Van Gijn J, van Dongen KJ. Computed tomography in the diagnosis of subarachnoid haemorrhage and ruptured aneurysm. Clin Neurol Neurosurg 1980;82:11-24.

16 Teasdale G, Jennett B. Assessment of coma and impaired consciousness. Lancet 1974;ii:81-4.

17 Devynck M, Pernollet M-G, Rosenfeld JB. Measurement of digitalis-like compound in plasma: application in studies of essential hypertension. $\mathrm{Br} \mathrm{Med} \mathcal{F}$ 1983;287:631-4.

18 Gault MH, Vasen SC, Longerich LL, et al. Plasma digitalis-like factors increase with salt loading. N Engl f Med 1983;309:1459.

19 Gruber KA, Whitaker JM, Buckalew VM. Endogenous digitalis-like substance in plasma of volume-expanded dogs. Nature 1980;287:743-5.

20 Graves SW, Brown B, Valdes R. An endogenous digoxin-like substance in patients with renal impairment. Ann Intern Med 1983;98:483-4.

21 Kaye GC, Williams A, Camm AJ. Digoxin-like immunoreactivity during atrial arrhythmias. Lancet 1986;i:689.

22 Klingmüller D, Weiler E, Kramer HJ. Digoxin-like natriuretic activity in the urine of salt loaded healthy subjects. Klin Wochenschr 1982;60:1249-53.

23 Poston L, Sewell RB, Wilkinson SP, et al. Evidence for a circulating sodium transport inhibitor in essential hypertension. $\mathrm{Br}$ Med F 1981;282:847-9.

24 MacGregor GA, Fenton S, Jadeh JA, et al. Evidence for a raised concentration of a circulating sodium transport inhibitor in essential hypertension. Br Med f 1981;283:1355-7.

25 Solomon RA, Post KD, McMurtry JG III. Depression of circulating blood volume in patients after subarachnoid hemorrhage: implications for management of symptomatic vasospasm. Neurosurgery 1984;15:354-61.

26 Heros RG, Zervas NT, Varsos V. Cerebral vasospasm after subarachnoid hemorrhage: an update. Ann Neurol 1983;14:599-608.

27 Pritz MB, Bianotta SL, Kindt G, et al. Treatment of patients with neurological deficits associated with cerebral vasospasm by intravascular volume expansion. Neurosurgery 1978;3:364-8.

28 Sundt TM Jr. Management of ischemic complications after subarachnoid hemorrhage. f Neurosurg 1975;43:418-25.

29 Crompton MR. Hypothalamic lesions following the rupture of cerebral berry aneurysms. Brain 1963;86:301-14.

30 Haupert GT, Sancho JM. Sodium transport inhibitor from bovine hypothalamus. Proc Natl Acad Sci USA 1979;76:4658-60.

31 Fishman MC. Endogenous digitalis-like activity in mammalian brain. Proc Natl Acad Sci USA 1979;76:4661-3.

32 Doshi R, Neil-Dwyer G. Hypothalamic and myocardial lesions after subarachnoid haemorrhage. I Neurol Neurosurg Psychiatry 1977;40:821-6.

(Accepted 11 February 1987)

\section{YEARS AGO}

The following authoritative particulars respecting the escape of an in-patient from Guy's Hospital, and his subsequent death, will be interesting, since the case has been the subject of a good deal of publicity. The deceased was admitted to the hospital on Tuesday fortnight, suffering from a poisoned hand. He got worse, and on Wednesday was removed to the strong room, where he was strapped down, under the care of a probationary nurse. He showed symptoms of mental aberration from the time of his admission, the most marked being his determination not to partake of food, which had to be administered through the nostrils and by the rectum. Being quiet and apparently manageable, the house-surgeon, on Thursday morning, perhaps unwisely, released one of his hands, with which he soon undid the other fastenings as soon as the house-surgeon left the room. It appears that it was during the interval in which the house-surgeon went to another ward to get a police-constable, who was watching a criminal case, to relieve the nurse, that the man made his escape. Help could have been instantly obtained from the ward above, had the nurse understood the working of the speaking tube; and after a struggle with the nurse, the patient escaped in a state of nudity into the street. Going to a police station, he appears to have told the police that he had escaped from a back room at the hospital, where some men had been trying to murder him. He was ultimately brought back to the hospital, where he died from cellulitis of the chest-walls and septicaemia. It came out in evidence that the man was not injured in any way by his escapade. (British Medical foumal 1887;ii:842.) 